\title{
Cyanide Ligand Assembly by Carbon Atom Transfer to an Iron Nitride
}

\author{
Jorge L. Martinez, ${ }^{\dagger}$ Hsiu-Jung Lin, ${ }^{\dagger}$ Wei-Tsung Lee, ${ }^{\dagger, \ddagger}$ Maren Pink, ${ }^{\dagger}$ Chun-Hsing Chen,${ }^{\dagger}$ Xinfeng \\ Gao, ${ }^{\dagger}$ Diane A. Dickie, ${ }^{\Perp,}$ and Jeremy M. Smith ${ }^{\dagger, *}$ \\ † Department of Chemistry, Indiana University, 8oo East Kirkwood Avenue, Bloomington, IN 47405, USA. \\ ' Department of Chemistry and Chemical Biology, University of New Mexico, Albuquerque, NM 87131, USA \\ Supporting Information Placeholder
}

\begin{abstract}
The new iron(IV) nitride complex $\mathrm{PhB}\left({ }^{\mathrm{i}} \mathrm{Pr}_{2} \mathrm{Im}\right)_{3} \mathrm{Fe} \equiv \mathrm{N}$ reacts with two equivalents of bis(diisopropylamino)cyclopropenylidene (BAC) to provide $\mathrm{PhB}\left({ }^{\mathrm{i}} \mathrm{Pr}_{2} \mathrm{Im}\right)_{3} \mathrm{Fe}(\mathrm{CN})\left(\mathrm{N}_{2}\right)(\mathrm{BAC})$. This unusual example of a four-electron reaction involves carbon atom transfer from BAC to create a cyanide ligand along with the alkyne ${ }^{i} \mathrm{Pr}_{2} \mathrm{~N}$ $\mathrm{C} \equiv \mathrm{C}-\mathrm{N}^{\mathrm{i}} \mathrm{Pr}_{2}$. The iron complex is in equilibrium with an $\mathrm{N}_{2}$-free species. Further reaction with $\mathrm{CO}$ leads to formation of a $\mathrm{CO}$ analogue, which can be independently prepared using $\mathrm{NaCN}$ as the cyanide source, while reaction with $\mathrm{B}\left(\mathrm{C}_{6} \mathrm{~F}_{5}\right)_{3}$ provides the cyanoborane derivative.
\end{abstract}

The venerable cyanide ligand occupies a notable spot in the annals of chemistry, starting with the preparation of Prussian blue in $1704 \cdot{ }^{1,2}$ Its good $\sigma$-donor and $\pi$-acceptor properties, combined with its negative charge and ambidentate properties make cyanide a unique and versatile ligand. For example, cyanide is able to stabilize a wide range of coordination numbers and oxidation states, with homoleptic complexes known for coordination numbers 2 to 8 and oxidation numbers o to $+5 .{ }^{3}$ Furthermore, cyanide is commonly used as a bridging group in the rational synthesis of well-defined metal clusters. ${ }^{4}$ Cyanide also plays an important role in biology, most notably as a ligand in the active site clusters of [NiFe] and [FeFe] hydrogenases, but also in other contexts, e.g. as defense agent in many plant species. ${ }^{5}$

Cyanide complexes are invariably prepared from alkali metal salts in relatively polar solvents.3,4 These cyanide salts are in turn manufactured from hydrogen cyanide, which is industrially produced from ammonia and methane, either in the presence (Andrussow process) or absence (BMA process) of air. Hydrogen cyanide is also a byproduct in the manufacture of acrylonitrile by the ammonoxidation of propylene (Sohio process). ${ }^{6}$

While their synthesis from alkali metal salts remains ubiquitous, other methods for the synthesis of transition metal cyanide complexes are known. ${ }^{7}$ Most notably, cyanide complexes can be prepared from organonitriles, e.g. by C-C oxidative addition. ${ }^{8}$ Cyanide ligands can also be accessed by reaction of carbonyl ligands with hexamethyldisilazide salts, ${ }^{9}$ or hexamethyldisilazide complexes with $\mathrm{CO} .{ }^{10}$ In biology, the carbon and nitrogen atoms of $\mathrm{CN}^{-}$are usually derived from amino acids. ${ }^{11}$ For example, $S$-adenosylmethionine lyses free tyrosine to produce the $\mathrm{CN}^{-}$and $\mathrm{CO}$ ligands of [FeFe] hydrogenase by a mechanism that involves radical intermediates. ${ }^{12}$

We have shown that iron(IV) nitride complexes supported by tris(carbene)borate ligands show a wide range of nitrogen atom transfer reactivity. ${ }^{13,14,15}$ These reactions include twoelectron nitrogen atom transfer to a range of phosphines, yielding a family of four-coordinate iron(II) spin crossover complexes. ${ }^{16}$ Based on these results, we hypothesized that stronger $\sigma$-donor groups would provide additional stabilization of the low spin state. This inspired us to investigate analogous nitrogen atom transfer from these iron nitride complexes to stabilized carbenes, which are generally better $\sigma$-donors than phosphines. ${ }^{17}$ In this work, we report that the reaction of an iron(IV) nitride with bis(diisopropylamino)cyclopropenylidene does not provide the anticipated ketiminate complex, but instead creates a cyanide ligand by carbon atom transfer from the carbene to the nitride, to the best of our knowledge a unique example of a four-electron carbon atom transfer reaction.

The new iron(IV) nitride complex $\mathrm{PhB}\left({ }^{\mathrm{i}} \mathrm{Pr}_{2} \mathrm{Im}\right)_{3} \mathrm{Fe} \equiv \mathrm{N} \mathbf{1}$ is prepared analogously to previously reported tris(carbene)borate iron(IV) nitrides. ${ }^{13}$ Specifically, irradiation of a mixture of $\mathrm{PhB}\left({ }^{\mathrm{i}} \mathrm{Pr}_{2} \mathrm{Im}\right)_{3} \mathrm{FeCl}$ and $\mathrm{NaN}_{3}$ leads to formation of $\mathbf{1}$ in good yield. The red diamagnetic complex shows similar features to previously reported iron(IV) nitrides, ${ }^{13}, 18$ most notably a resonance at $\delta=1003 \mathrm{ppm}$ in the ${ }^{15} \mathrm{~N}$ NMR spectrum that is characteristic of the nitride ligand.

Complex 1 reacts with two equivalents of the isolable carbene bis(diisopropylamino)cyclopropenylidene (BAC) ${ }^{19}$ to yield diamagnetic $\mathrm{PhB}\left({ }^{\mathrm{i}} \mathrm{Pr}_{2} \mathrm{Im}\right)_{3} \mathrm{Fe}\left(\mathrm{N}_{2}\right)(\mathrm{CN})(\mathrm{BAC})$ 2, which has been structurally characterized by single crystal X-ray diffraction (Figure 1). Reaction with one equivalent of BAC results in only $50 \%$ conversion to the product, with half of the iron starting material unreacted. The molecular structure of 2 reveals the complex to have a six-coordinate iron center that is bound to the tripodal tris(carbene)borate, a BAC ligand and $\mathrm{N}_{2}$. The most remarkable feature of the structure is the identity of the remaining ligand, which has been formulated as cyanide on the basis of crystallographic and spectroscopic data, as well as reactivity studies and independent synthesis, as discussed in more detail below. 


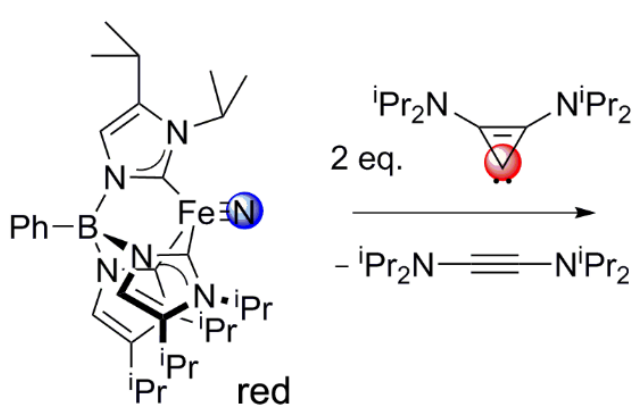

1

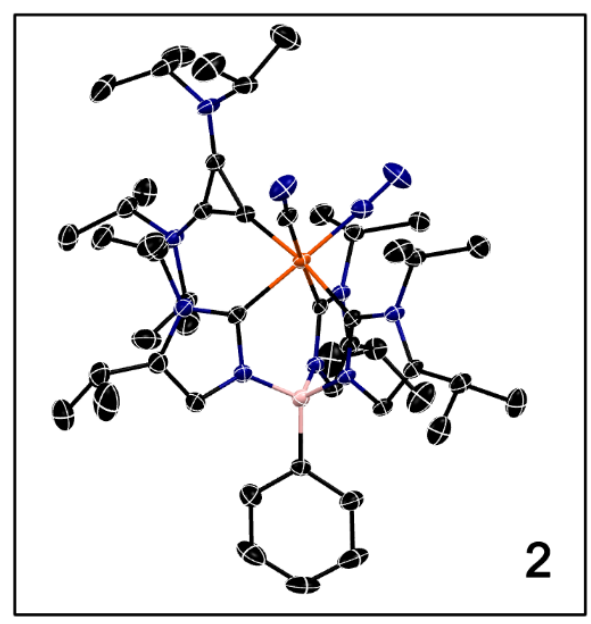

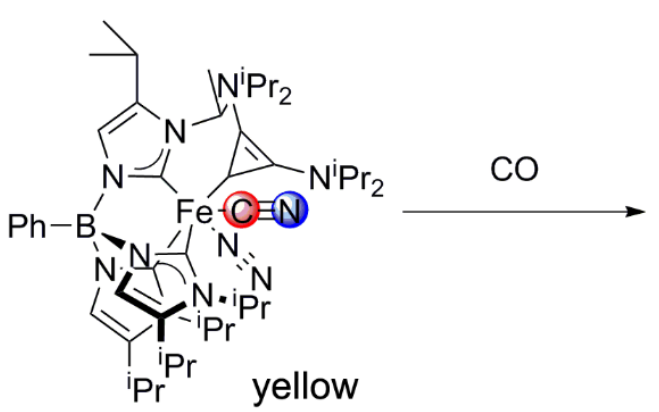

2

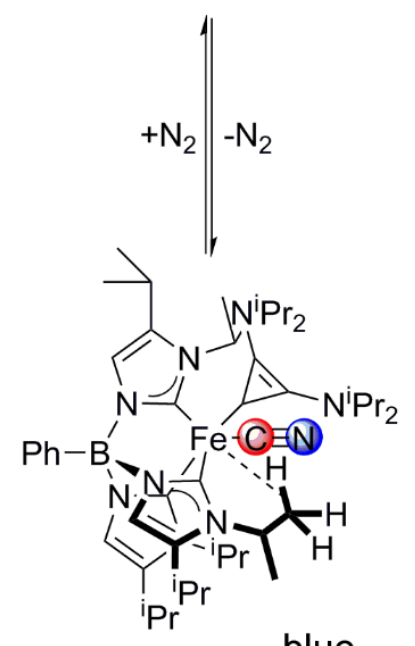

blue

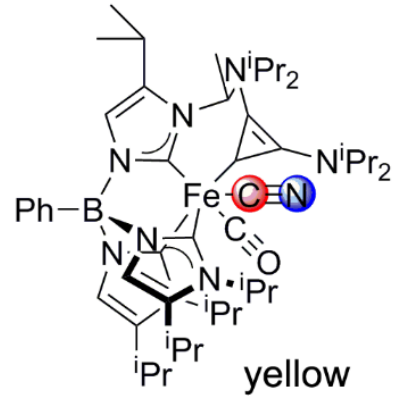

4

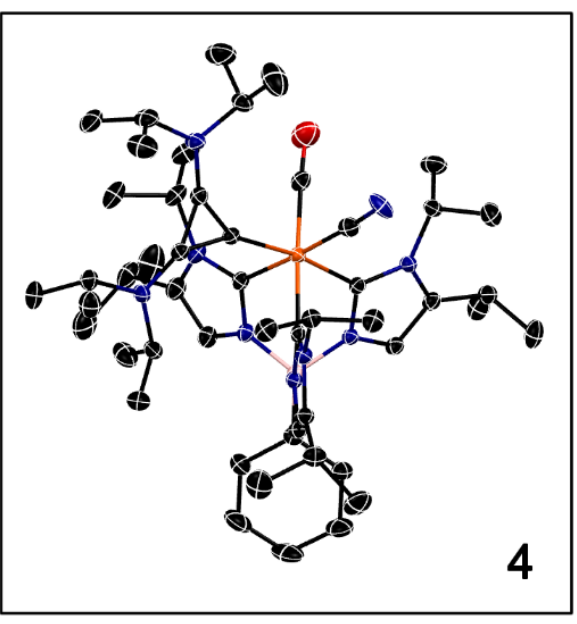

Figure 1. Synthesis of complexes. Insets show the structures of complexes $\mathbf{2}$ and $\mathbf{4}$ as determined by single crystal X-ray diffraction. Thermal ellipsoids shown at 50\% probability, hydrogen atoms omitted for clarity. Black, blue, pink and orange ellipsoids represent C, N, B and Fe atoms, respectively.

Aside from the unexpected coordination sphere, the metrical parameters of $\mathbf{2}$ are typical for a low spin iron(II) complex. Thus, the bond lengths between iron and the cyanide (1.933(2) $\AA ̊$ ), tris(carbene)borate (1.975(2) - 2.011(2) $\AA$ ) ligands are typical for low spin iron iron(II), 3,4,16 while the Fe-BAC bond length (1.974(2) $\AA$ ) is slightly shorter than observed in iron(o) BAC complexes. ${ }^{20}$ Similarly, the $\mathrm{C} \equiv \mathrm{N}$ bond length (1.155(2) $\AA$ ) and $\mathrm{Fe}-\mathrm{C} \equiv \mathrm{N}$ bond angle $\left(174.9(2)^{\circ}\right)$ are within the expected range for a low spin iron(II) cyanide complex.

It is notable that while the crystals of $\mathbf{2}$ are yellow, room temperature solutions of the complex are blue. The blue color reversibly changes to yellow when $\mathbf{2}$ is cooled, which in turn becomes blue under vacuum, suggesting that the $\mathrm{N}_{2}$ ligand is labile. This hypothesis is confirmed through the structural characterization of blue crystals grown at room temperature, with the crystallographic data also collected at room temperature so as to avoid $\mathrm{N}_{2}$ binding. The molecular structure reveals that 3 is a five-coordinate iron complex formed by $\mathrm{N}_{2}$ loss from 2. While detailed structural insight is limited by the quality of the data, the short distance between iron and one of the tris(carbene)borate isopropyl methyl groups (2.81(1) $\AA$ ) suggests that loss of the $\mathrm{N}_{2}$ ligand is accompanied by the formation of an interaction between iron and the isopropyl group.
The solution behavior of $\mathbf{2}$ is complex, as revealed by variable temperature ${ }^{1} \mathrm{H}$ NMR spectroscopy. At $-50{ }^{\circ} \mathrm{C}$, 10 resonances for the methine protons of the 10 inequivalent isopropyl groups are observed in the ${ }^{1} \mathrm{H}$ NMR spectrum, consistent with the low symmetry structure observed for $\mathbf{2}$ in the solid state. Increasing the temperature leads to broadening and coalescence of the resonances, suggesting reversible $\mathrm{N}_{2}$ binding that is rapid on the NMR timescale. Consistent with this hypothesis, a single broadened resonance $(\delta=342.3 \mathrm{ppm})$ is observed in the room temperature ${ }^{15} \mathrm{~N}$ NMR spectrum of a sample of 2 prepared under an atmosphere of ${ }^{15} \mathrm{~N}_{2}{ }^{21}$

The cyanide ligand has been additionally characterized by spectroscopic methods. The ${ }^{15} \mathrm{~N}$ NMR spectrum of ${ }^{15} \mathrm{~N}-\mathrm{en}-$ riched $2 / 3$ (prepared from a sample of 1 containing $50 \%{ }^{15} \mathrm{~N}$ enriched nitride) shows a single resonance whose chemical shift $(\delta=318 \mathrm{ppm})$ compares well with that observed for the cyanide ligand in $\left[\mathrm{Fe}\left(\mathrm{C}^{15} \mathrm{~N}\right)_{6}\right]^{4-}(\delta=284 \mathrm{ppm}) .^{22}$ The solution IR spectrum of $\mathbf{2}$ shows two strong bands that are assigned to the $\mathrm{N}_{2}\left(v_{\mathrm{NN}}=2070 \mathrm{~cm}^{-1}\right)$ and $\mathrm{CN}^{-}\left(v_{\mathrm{CN}}=2094 \mathrm{~cm}^{-1}\right)$ ligands, respectively. Consistent with loss of the $\mathrm{N}_{2}$ ligand, only the latter band is observed in the solid state IR spectrum of blue 3 . The frequency of this band is typical for that of a terminal cyanide ligand. ${ }^{4}$ 

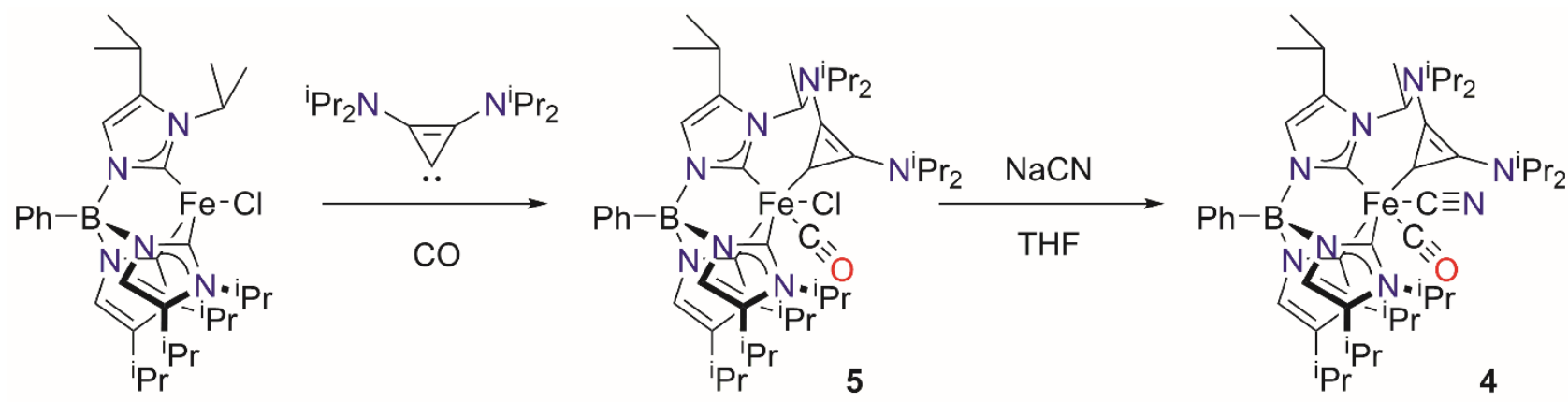

The other product of the reaction between $\mathbf{1}$ and $\mathrm{BAC}$ is the alkyne ${ }^{\mathrm{i}} \mathrm{Pr}_{2} \mathrm{~N}-\mathrm{C} \equiv \mathrm{C}-\mathrm{N}^{\mathrm{i}} \mathrm{Pr}_{2}$, which has been characterized by multinuclear NMR spectroscopy and CI-MS. A notable spectroscopic feature of this compound is the dramatically downfield shift $(\delta=206 \mathrm{ppm})$ of the alkyne carbon resonance in the ${ }^{13} \mathrm{C}\left\{{ }^{1} \mathrm{H}\right\}$ NMR spectrum, likely a consequence of the presence of the electron-withdrawing nitrogen atoms.

The combined structural and spectroscopic data therefore reveals that the reaction between $\mathbf{1}$ and BAC results in carbon atom transfer to the nitride, leading to the assembly of a new cyanide ligand. To the best of our knowledge, this is a unique example of a four electron atom transfer reaction, with two of the electrons provided by iron and two by the cyclopropenylidene.

Preliminary reactivity studies confirm the structural formulation. Exposing 2/3 to an atmosphere of carbon monoxide results in $\mathrm{N}_{2}$ ligand substitution and quantitative formation of the $\mathrm{CO}$ analogue $\mathrm{PhB}\left({ }^{\mathrm{i}} \mathrm{Pr}_{2} \mathrm{Im}\right)_{3} \mathrm{Fe}(\mathrm{CO})(\mathrm{CN})(\mathrm{BAC})$ 4, which has been characterized by single crystal $\mathrm{X}$-ray diffraction (Figure 1). The metrical parameters 4 are unexceptional for a low-spin iron(II) complex, with typical Fe-C(imidazolylidene) (1.981(1)

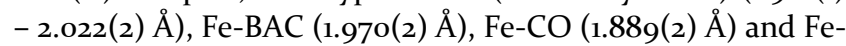
$\mathrm{CN}$ (1.806(2) $\AA$ ) bond lengths. The Fe-C-N bond angle is close to linear $\left(175.9(2)^{\circ}\right)$.

In contrast to 2, there is no evidence for reversible ligand binding in 4 . Thus, the room temperature ${ }^{1} \mathrm{H}$ NMR spectrum is consistent with the low-symmetry structure observed in the solid state. For example, six well-resolved septets assigned to the tris(carbene)borate isopropyl methine groups are observed in the room temperature spectrum, as expected for $C_{1}$ symmetry. The resonances assigned to the cyclopropenylidene ligand are broadened, suggesting restricted rotation around the $\mathrm{Fe}-\mathrm{C}$ bond. The infrared spectrum reveals bands at $2078 \mathrm{~cm}^{-1}$ and $1900 \mathrm{~cm}^{-1}$, which are assigned as $v_{\mathrm{CN}}$ and $v_{\mathrm{CO}}$, respectively. When complex 4 is prepared from ${ }^{13} \mathrm{CO}$, the band at $1900 \mathrm{~cm}^{-1}$ is replaced by a new band at $1850 \mathrm{~cm}^{-1}$, while the band at $2078 \mathrm{~cm}^{-1}$ remains unchanged. This observation provides further evidence that the latter band is associated with the cyanide ligand. The ${ }^{15} \mathrm{~N}$ NMR spectrum of an isotopicallyenriched sample shows a single resonance for the cyanide ligand, whose chemical shift is essentially the same as $\mathbf{2} / 3(\delta=$ $315 \mathrm{ppm})$.

Complex 4 can be accessed through an alternate synthetic route (Scheme 1). Specifically, the reaction of $\mathrm{PhB}\left({ }^{\mathrm{i}} \mathrm{Pr}_{2} \mathrm{Im}\right)_{3} \mathrm{FeCl}$ with $\mathrm{CO}$ in the presence of 1 equiv. cyclopropenylidene provides the spectroscopically characterized diamagnetic complex $\mathrm{PhB}\left({ }^{\mathrm{i}} \mathrm{Pr}_{2} \mathrm{Im}\right)_{3} \mathrm{FeCl}(\mathrm{CO})(\mathrm{BAC}){ }_{5}\left(v_{\mathrm{CO}}=1900\right.$ $\mathrm{cm}^{-1}$ ), which in turn reacts with excess $\mathrm{NaCN}$ to provide 4 in high yield. The spectroscopic signatures of the complex prepared by this route are identical to those observed for the complex whose synthesis originates from 1.

As expected, the newly formed cyanide ligand shows Lewis basic properties. Thus, $2 / 3$ react with $\mathrm{B}\left(\mathrm{C}_{6} \mathrm{~F}_{5}\right)_{3}$ to yield the diamagnetic adduct $\mathrm{PhB}\left({ }^{\mathrm{i}} \mathrm{Pr}_{2} \mathrm{Im}\right)_{3} \mathrm{Fe}\left(\mathrm{N}_{2}\right)\left(\mathrm{CNB}\left(\mathrm{C}_{6} \mathrm{~F}_{5}\right)_{3}\right)(\mathrm{BAC}) 6$. As has been observed for other adducts between cyanide ligands and $\mathrm{B}\left(\mathrm{C}_{6} \mathrm{~F}_{5}\right)_{3}$, the cyanide stretch moves to a higher frequency in the IR spectrum $\left(v_{\mathrm{CN}}=2133 \mathrm{~cm}^{-1}\right),{ }^{23}$ while the cyanide resonance shifts upfield in the ${ }^{15} \mathrm{~N}$ NMR spectrum $(\delta=183$ ppm). ${ }^{24,25}$

A plausible mechanism for the formation of $\mathbf{2}$ involves the initial formation of an iron(II) ketiminate complex from $\mathbf{1}$ and one equivalent of BAC. This complex undergoes a [2+2] cycloreversion reaction that extrudes the alkyne and generates an isocyanide ligand. A related transformation involving pyrolytic alkyne extrusion from a cyclopropenone has been reported. ${ }^{26}$ Complex 2 is formed via a sequence of transformations involving isocyanide isomerization and coordination of $\mathrm{BAC}$ and $\mathrm{N}_{2}$ ligands, although the timing of these steps is unclear.

In summary, we have established a new synthetic route to the cyanide ligand, specifically through a four-electron reaction involving carbon atom transfer from bis(diisopropylamino)cyclopropenylidene to a nitride ligand. We anticipate that this elemental synthesis will find application to the synthesis of other cyanide ligands. More generally, this readily accessible and stable carbene may also serve as a carbon atom transfer reagent in other synthetic applications, for example in the preparation of the metal carbide complexes. ${ }^{27}$

\section{ASSOCIATED CONTENT}

\section{Supporting Information}

Full experimental and characterization details. This material is available free of charge via the Internet at http://pubs.acs.org.

\section{AUTHOR INFORMATION}

\section{Corresponding Author}

Jeremy M. Smith: smithg62@indiana.edu

\section{Present Addresses}

‡ Department of Chemistry and Biochemistry, Loyola University Chicago, Chicago, IL 6o66o, USA. 
' Department of Chemistry, MS 015, Brandeis University, 415 South Street, Waltham, MA 02453, USA

\section{Notes}

The authors declare no competing financial interests.

\section{ACKNOWLEDGMENT}

\author{
${ }^{1}$ History of Prussian Blue: Kraft, A. Bull. Hist. Chem. 2oo8, 33, 61- \\ 67. \\ 2 First reports of Prussian Blue synthesis: (a) Woodward, J. Phil. \\ Trans. 1724, 33, 15-17; (b) Brown, J. Phil. Trans. 1724, 33, 17-24. \\ 3 Sharpe, A.G. "The Chemistry of Cyano Complexes of the Transi- \\ tion Metals" Academic Press, London: 1976
}

4 (a) Dunbar, K.; Heintz, R.A. Prog. Inorg. Chem. 1997, 45, 283-391; (b) Shatruk, M.; Avendana, C.; Dunbar, K. Prog. Inorg. Chem. 2009 $56,155-334$.

${ }^{5}$ Bjarnholt, N.; Møller, B.L. Phytochemistry 20o8, 69, 1947-1961.

6 Pesce, L.D. "Cyanides" in Kirk-Othmer Encylcopedia of Chemical Technology $5^{\text {th }}$ Ed., John Wiley \& Sons, Hoboken: 2004.

${ }^{7}$ Fehlhammer, W.P.; Fritz, M. Chem. Rev. 1993, 93, 1243-128o.

8 (a) Garcia, J.J.; Jones, W.D. Organometallics 20oo, 19, 5544-5545; (b) Garcia, J.J.; Brunkan, N.M.; Jones, W.D. J. Am. Chem. Soc. 20o2, 124, 9547-9555; (c) Ateșin, T.A.; Li, T; Lachaize, S.; Brennessel, W.W.; Garcia, J.J.; Jones, W.D. J. Am. Chem. Soc. 20o8, 129, 7562-7569; (d) Acosta-Ramírez, A.; Flores-Álamo, M.; Jones, W.D.; Garcia, J.J. Organometallics 2oo8, 27, 1834-1840; (e) Ateșin, T.A.; Li, T; Lachaize, S.; Garcia, J.J.; Jones, W.D. Organometallics 2008, 27, 3811-3817; (f) Li, T.; Garcia, J.J.; Brennessel, W.W.; Jones, W.D. Organometallics 2010, 29 , 2430-2445; (g) Evans, M.E.; Li, T. Jones, W.D. J. Am. Chem. Soc. 2010 132, 16278-16284; (h) Swartz, B.D.; Brennessel, W.W.; Jones, W.D. Organometallics 2011, 30, 1523-1529; (i) Xu, H.; Williard, P.G.; Bernskoetter, W. Organometallics 2012, 31, 1588-1590.

9 (a) Behrens, H.; Ranley, H.-J.; Lindner, E. Z. Anorg. Allg. Chem. 1974, 409, 299-310; (b) Behrens, H.; Moll, M.; Popp, W.; Würstl, P. Z. Naturfosch. B 1977, 32, 1227-1229; (c) Moll, M.; Behrens, H.; Merbach, P.; Trummer, K.-H.; Thiele, G.; Wittmann, K. P. Z. Naturfosch. B 1986, 41, 606-616; (d) Lyon, E.J.; Georgakaki, I.P.; Riebenspies, J.J.; Darensbourg, M.Y. Angew. Chem. Int. Ed. 1999, 38, 3178-3180.

10 Sellmann, D.; Geipel, F.; Heinemann, F.W. Chem. Eur. J. 20oo, 6 , 4279-4284.

${ }^{11}$ Swanson, K.D.; Duffus, B.R.; Beard, T.E.; Peters, J.W.; Broderick, J.B. Eur. J. Inorg. Chem. 2011, 935-947.

12 (a) Driesner, R.C.; Challand, M.R.; McGlynn, S.E.; Shepard, E.M.; Boyd, E.S.; Broderick, J.B.; Peters, J.W.; Loach, P.L. Angew. Chem. Int. Ed. 2010, 49, 1687-1690; (b) Shepard, E.M.; Duffus, B.R.; George, S.J.; McGlynn, S.E.; Challand, M.R.; Swanson, K.D.; Roach, P.L.; Cramer, S.P.; Peters, J.W.; Broderick, J.B. J. Am. Chem. Soc. 2010, 132, 92479249; (c) Kuchenreuther, J.M.; George, S.J.; Grady-Smith, C.S.; Cramer, S.P.; Swartz, J.R. PLOS ONE, 2011, 6, e20346; (d) Kuchenreuther, J.M.; Myers, W.K.; Stich, T.A.; George, S.J.; NejatyJahromy, Y.; Swartz, J.R.; Britt, R.D. Science 2013, 342, 472-475; (e) Suess, D.L.M.; Kuchenreuther, J.M.; De La Paz, L.; Swartz, J.R.; Britt, R.D. Inorg. Chem. 2015, 55, 478-487; (f) Suess, D.L.M.; Pham, C.C.; Bürstel, I.; Swartz, J.R.; Cramer, S.P.; Britt, R.D. J. Am. Chem. Soc. 2016, 138, 11491149.

13 (a) Scepaniak, J.J.; Fulton, M.D.; Bontchev, R.P.; Duesler, E.N.; Kirk, M.L.; Smith, J.M. J. Am. Chem. Soc. 2008, 130, 10515 (b) Scepaniak, J.J.; Young, J.A; Bontchev, R.P.; Smith, J.M. Angew. Chem. Int. Ed. 2009, $48,3158$.

14 Smith, J.M.; Subedi, D. Dalton Trans. 2012, 41, 1423.

15 (a) Scepaniak, J.J.; Bontchev, R.P.; Johnson, D.L.; Smith, J.M. Angew. Chem. Int. Ed.2011, 50, 6630; (b) Scepaniak, J.J.; Margarit, C.G.;
Funding from Indiana University, the DOE (DE-FGo2o8ER15996) and NSF (CHE-1566258) is gratefully acknowledged. The Bruker X8 X-ray diffractometer was purchased via an NSF CRIF:MU award to the University of New Mexico, CHE-0443580.

\section{REFERENCES}

Harvey, J.N.; Smith, J.M. Inorg. Chem. 2011, 50, 9508; (c) Lee, W.-T.; Juarez, R.A.; Scepaniak, J.J.; Muñoz, S.B; Dickie, D.A.; Wang, H.; Smith, J.M. Inorg. Chem. 2014, 53, 8425; (d) Muñoz, III, S.B.; Lee, W.T.; Dickie, D.A.; Scepaniak, J.J.; Subedi, D.; Pink, M.; Johnson, M.D.; Smith, J.M. Angew. Chem. Int. Ed. 2015, 54, 1060o; (e) Ding, M.; Rouzières, M.; Losovyj, Y.; Pink, M.; Clérac, R.; Smith, J.M. Inorg. Chem. 2015, 54, 9075 .

16 (a) Scepaniak, J.J.; Harris, T.D.; Vogel, C.S.; Sutter, J.; Meyer, K.; Smith, J.M. J. Am. Chem. Soc.2011, 133, 3824-3827; (b) Mathonière, C.; Lin, H.-J.; Siretanu, D.; Clérac, R.; Smith, J.M. J. Am. Chem. Soc. 2013 135, 19083-19086; (c) Lin, H-.J.; Siretanu, D.; Dickie, D.A.; Subedi, D.; Scepaniak, J.J.; Mitcov, D.; Clérac, R.; Smith, J.M. J. Am. Chem. Soc. 2014, 136, 13326-13332.

17 Selected reviews: (a) Cavallo, L.; Correa, A.; Costabile, C.; Jacobsen, H. J. Organomet. Chem. 2005, 69o, 5407-5413; (b) Díez-González, S.; Nolan, S.P. Coord. Chem. Rev. 2007, 251, 874-883; (c) Schuster, O.; Yang, L.; Raubenheimer, H.G.; Albrecht, M. Chem. Rev. 2009, 109, 3445-3478; (d) Melaimi, M.; Soleilhavoup, M.; Bertrand, G. Angew. Chem. Int. Ed. 2010, 49, 8810-8849.

18 (a) Betley, T. A.; Peters, J. C. J. Am. Chem. Soc. 2004, 126, 6252-6254; (b) Vogel, C.; Heinemann, F. W.; Sutter, J.; Anthon, C.; Meyer, K. Angew. Chem., Int. Ed. 2008, 47, 2681- 2684.

19 (a) Lavallo, V.; Canac, Y. Donnadieu, B.; Schoeller, W.W.; Bertrand, G. Science 2006, 312, 722-724; (b) Lavallo, V.; Canac, Y.; Donnadieu, B.; Schoeller, W.W.; Bertrand, G. Angew. Chem. Int. Ed. 20o6, 45,6652 .

20 Lavallo, V.; El-Batta, A.; Bertrand, G.; Grubbs, R.H. Angew. Chem. Int. Ed. 2011, 50, 268-271.

21 This chemical shift is comparable to observations for other iron(II) complexes containing terminal $\mathrm{N}_{2}$ ligands, see: Hazari, $\mathrm{N}$. Chem. Soc. Rev. 2o10, 39, 4044-4056.

${ }^{22}$ Sano, M.; Yoshikawa, Y.; Yamatera, H. Inorg. Chem. 1982, 21, 25212523.

23 Manor, B.C.; Ringenberg, M.R.; Rauchfuss, T.B. Inorg. Chem. 2014, 53, 7241-7247.

24 Finze, M.; Bernhardt, E.; Willner, H.; Lehmann, C.W. Organometallics 2006, 25, 3070-3075.

${ }^{25}$ No B-N coupling is observed in the ${ }^{15} \mathrm{~N}$ NMR spectrum; typical $J_{\mathrm{BN}}<10 \mathrm{~Hz}$, see Wrackmeyer, B.; Tok, O.L. Z. Naturfosch. 2007, 62b, 220-224; (b) Nöth, H.; Wrackmeyer, B. "Nuclear Magnetic Resonance Spectroscopy of Boron Compounds" Springer-Verlag, Berlin: 1978.

26 Wilcox, C.; Breslow, R. Tetrahedron Lett. 1980, 21, 3241-3242.

27 (a) Peters, J.C.; Odom, A.L.; Cummins, C.C. Chem. Commun. 1997, 1995-1996; (b) Enriquez, A.E.; White, P.S.; Templeton, J.L. J. Am. Chem. Soc. 2001, 123, 4992-5002; (c) Greco, J.B.; Peters, J.C.; Baker, T.A.; Davis, W.M.; Cummins, C.C.; Wu, G. J. Am. Chem. Soc. 2oo1, 123 5003-5013; (d) Carlson, R.G.; Gile, M.A.; Heppert, J.A.; Mason, M.H.; Powell, D.R.; Vander Velde, D.; Vilain, J.M. J. Am. Chem. Soc. 2002, 124, 1580-1581; (e) Caskey, S.R; Stewart, M.H.; Kivela, J.E.; Sootsman, J.R.; Johnson, M.J.A.; Kampf, J.W. J. Am. Chem. Soc. 20o6, 127, 1675016751; (f) Stewart, M.H.; Johnson, M.J.A.; Kampf, J.W. Organometallics 2007, 26, 5102-5110; (g) Cordner, R.L.; Hill, A.F.; Wagler, J. Organometallics 2008, 27, 5177-5179. 
SYNOPSIS TOC.

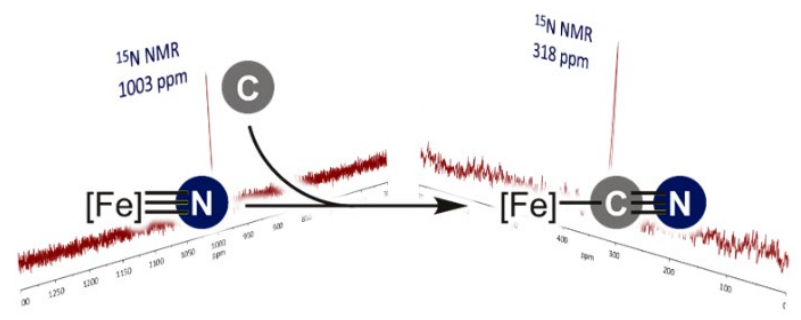

